\title{
INFECÇÃO CITOMEGÁLICA PÓS-TRANSPLANTE RENAL
}

\author{
Cytomegalovirus infection after kidney transplantation
}

Thamiris Becker Scheffel', Regina Barbosa Schroeder², Elizete Keitel², Jorge Milton Neumann², Liliana Portal Weber ${ }^{1}$

\section{RESUMO}

Introdução: O transplante renal é o mais realizado mundialmente. No entanto, apesar de os transplantes renais terem, na maioria das vezes, resultados satisfatórios, o uso contínuo de imunossupressores pode ter impacto negativo sobre o paciente, deixando-o suscetível a complicações infecciosas. Uma das principais complicações é a infecção pelo citomegalovírus, que ocorre principalmente nos primeiros três meses após o transplante, sendo uma importante causa de morbidade e mortalidade para esses pacientes. Atualmente, para a redução do risco de doença citomegálica, existem duas estratégias terapêuticas: terapia preemptiva e profilaxia. Porém, apesar de os protocolos terapêuticos estarem estabelecidos, a resistência viral e a recidiva da doença citomegálica têm colocado esses pacientes novamente em discussão. Nesse contexto, o objetivo do estudo é realizar uma revisão narrativa acerca da infecção citomegálica em transplantados renais, abordando as características virais no desenvolvimento da infecção e da doença citomegálica, bem como os fatores de risco e o impacto no paciente, a preferência pelo método de antigenemia pp65 ou o uso de testes de ácidos nucleicos (NAT) no diagnóstico e as atuais estratégias de tratamento. Para tal revisão, bases de dados foram consultadas, sendo selecionados artigos atuais com tema relevante sobre o assunto.

Descritores: Citomegalovírus, Infecções por Citomegalovírus, Transplante de Rim.

\section{Instituição:}

${ }^{1}$ Centro de Ciências Biológicas e da Saúde, Universidade de Caxias do Sul, Caxias do Sul/RS - Brasil.

${ }^{2}$ Laboratório de Imunologia de Transplantes, Santa Casa de Misericórdia de Porto Alegre, Porto Alegre/RS - Brasil

Correspondência:

Thamiris Becker Scheffel

Rua Chile, 895 - Ap. 202 - CEP 90670-140 - Porto Alegre/RS

Tel: (54) 9983.4287.

E-mail: mih.scheffel@yahoo.com.br

\section{INTRODUÇÃO}

O transplante renal é o mais realizado mundialmente dentre os transplantes de órgãos sólidos. ${ }^{1} \mathrm{De}$ acordo com o Registro Brasileiro de Transplantes publicado anualmente pela Associação Brasileira de Transplantes de Órgãos, em 2013 foram realizados aproximadamente 7.500 transplantes de órgãos sólidos no Brasil, sendo $73 \%$ correspondentes a transplantes renais. ${ }^{2}$ Apesar de os transplantes renais terem, na maioria das vezes, resultados satisfatórios, inúmeros fatores de risco estão associados ao período pós-transplante, entre eles a rejeição ao enxerto, o que aponta a necessidade de utilização permanente de terapia imunossupressora. ${ }^{3}$

O uso contínuo de imunossupressores pode ter impacto negativo sobre o paciente, uma vez que reduz deliberadamente a atividade e a eficiência do sistema imunológico, deixando-o suscetível a diversas complicações, principalmente infecciosas. ${ }^{4-6}$ 
A incidência e a severidade dos eventos infecciosos são maiores nos primeiros meses após o transplante, período em que a terapia imunossupressora também é mais intensa. Em média, $80 \%$ dos receptores renais apresentam alguma complicação infecciosa durante o primeiro ano de acompanhamento. ${ }^{7}$

Uma das principais complicações em transplantes de órgãos sólidos é a infecção pelo citomegalovírus (CMV), que ocorre principalmente nos primeiros três meses após o transplante, sendo uma importante causa de morbidade nesses pacientes. Estima-se que 50 a $80 \%$ desenvolvem infecção ativa e 20 a $60 \%$, doença citomegálica. ${ }^{8-10} \mathrm{O}$ status sorológico do doador e do receptor, bem como o protocolo imunossupressor adotado, são extremamente importantes na determinação do risco de infecção e de doença citomegálica. 8,10

As formas clínicas dependem da intensidade da imunossupressão e do tipo de infecção, primária ou secundária. A infecção está associada a um aumento da imunogenicidade do órgão transplantado, com consequente aumento do risco de rejeição, além de doença linfoproliferativa pós-transplante, nefropatia crônica do enxerto e outras infecções oportunistas. ${ }^{11}$ Outro sério problema é a mimetização de sintomas de rejeição ao enxerto causada pela infecção citomegálica, devido ao efeito imunomodulador do vírus, sendo essencial o diagnóstico diferencial de forma específica e precoce. ${ }^{10}$

Para tanto, a pesquisa da antigenemia pp65 tem sido utilizada para o diagnóstico de infecção citomegálica ativa, desde o final da década de 80 , tendo hoje um papel considerável no estabelecimento da terapia preemptiva. O diagnóstico baseia-se na utilização de anticorpo monoclonal contra a proteína viral pp65, informando diretamente, ao final do ensaio, o número de células infectadas no sangue periférico. Em contrapartida, os métodos baseados em amplificação de ácidos nucleicos, apesar de terem revolucionado a aplicabilidade clínica do laboratório de virologia na última década, têm sido bastante discutidos uma vez que podem não distinguir o diagnóstico de infecção latente e ativa. ${ }^{12}$

O diagnóstico precoce de infecção citomegálica ativa e a compreensão do quadro clínico do paciente são fundamentais para o estabelecimento terapêutico, evitando com isso o desenvolvimento de doença no órgão transplantado, bem como complicações ainda mais graves. ${ }^{10}$

Em vista disso, o objetivo deste estudo é realizar uma revisão narrativa acerca da infecção por citomegalovírus em transplantados renais, abordando as características virais no desenvolvimento da infecção e da doença citomegálica, bem como os fatores de risco e o impacto no paciente, a preferência pelo método de antigenemia pp65 ou o uso de testes de ácidos nucleicos (NAT) no diagnóstico de infecção ativa e as atuais estratégias de tratamento.

Para tal revisão, as bases de dados PubMED, Science Direct, portal de periódicos Capes, LILACS e SciELO foram consultadas, sendo selecionados artigos relevantes publicados a partir de 2007.

\section{Transplante renal}

A doença renal crônica em fase terminal é uma condição extremamente debilitante, associada a significativa morbidade, mortalidade e elevado custo terapêutico. Para pacientes nessa condição, o transplante renal tornou-se a melhor escolha terapêutica, proporcionando benefícios na sobrevida, qualidade de vida e no custoefetividade..$^{13,14}$

De acordo com a Organização Mundial de Saúde (OMS), o transplante de rim é o mais realizado mundialmente, dentre os transplantes de órgãos sólidos.1 Somente no período de janeiro a setembro de 2014 , foram realizados 4.221 transplantes renais no país, sendo esse o número mais significativo dentre os transplantes de órgãos sólidos. Contudo, esse número ainda está muito aquém do número de pacientes urêmicos em lista de espera, o que representa 18.290 indivíduos. ${ }^{15}$

O transplante renal pode ser realizado a partir de doador vivo ou falecido. ${ }^{7}$ Hoje, no Brasil, o número de doadores renais falecidos é maior (3.166 indivíduos) em relação ao número de doadores vivos (1.055 indivíduos).15 Sabe-se que o transplante a partir de doador falecido está relacionado ao maior risco de episódios de rejeição e, ainda, de complicações infecciosas. ${ }^{7}$

Para a seleção de um doador adequado (no caso de doadores vivos) alguns critérios devem ser levados em consideração para aumentar a probabilidade de sucesso do transplante. De modo geral, o doador deve ser saudável, adulto, com idade superior a 21 anos (máximo 70 anos), ter função renal normal e não apresentar evidências de risco de doença renal ou comprometimento de outros órgãos vitais após a doação. Doadores vivos com grau de parentesco próximo ao receptor apresentam resultados de transplante superiores àqueles realizados com rim de doadores falecidos ou doadores vivos sem grau de parentesco. ${ }^{16}$

No transplante, o primeiro aspecto a ser considerado é a compatibilidade $A B O$ entre doador e receptor. $A$ importância dessa compatibilidade está baseada no fato de os antígenos do sistema ABO serem expressos na superfície das células endoteliais, podendo servir de alvo para as isohemaglutininas naturais presentes no sangue do receptor. Tais anticorpos são eficientes fixadores de complemento e poderiam mediar a rejeição hiperaguda ao enxerto. ${ }^{17}$ 
Além disso, o processo de seleção de doadores compatíveis requer a tipagem HLA (Human Leucocyte Antigens). As moléculas HLA são codificadas por genes localizados no braço curto do cromossomo 6, na região do MHC (major histocompatibility complex). Os genes de classe I na região do MHC (HLA-A, B e C) codificam glicoproteínas que são expressas na superfície de todas as células nucleadas e são responsáveis por apresentar os peptídeos endógenos ou virais às células T CD8+. $\mathrm{Na}$ região de classe II, os loci HLA DR, DQ e DP codificam glicoproteínas expressas na superfície das células apresentadoras de antígenos (APCs) que estão envolvidas na apresentação de peptídeos exógenos aos receptores das células T CD4+. As moléculas do MHC estão fortemente associadas ao alorreconhecimento de antígenos em transplantes de órgãos, podendo uma incompatibilidade estar relacionada a um processo imediato de rejeição. ${ }^{18}$

Outro teste laboratorial necessário é a prova cruzada ou "cross-match", empregada para avaliar se o receptor é sensibilizado contra antígenos de histocompatibilidade do doador. Essa prova é geralmente realizada no momento em que se encontra um doador compatível e imediatamente antes da realização do transplante. A principal função da prova cruzada é avaliar o risco de rejeição humoral (hiperaguda). Para tanto, basicamente, uma amostra de soro do receptor é combinada in vitro com linfócitos do doador e, ao final, no caso de reação positiva, ou seja, quando existem anticorpos específicos antidoador em circulação, se for realizado o transplante, este poderá ser rapidamente rejeitado. Comumente, observa-se reação positiva em pacientes que foram submetidos a transfusões múltiplas, mulheres com mais de uma gestação ou indivíduos que já foram previamente transplantados. ${ }^{17}$

Esses e outros exames, incluindo sorologia para doença de Chagas, citomegalovírus, vírus da imunodeficiência humana (HIV, sigla em inglês), hepatite $B$ e $C$, toxoplasmose, sífilis, vírus BK e vírus Epstein Barr, são realizados a fim de se garantir o sucesso do transplante e evitar episódio de rejeição. ${ }^{3,19}$

A rejeição caracteriza-se por uma reação de hipersensibilidade que envolve principalmente a ação de linfócitos $T$ e monócitos, podendo ser classificada em hiperaguda, aguda, aguda tardia ou crônica. Outras classificações também são adotadas e levam em consideração alterações fisiopatológicas, gravidade, resposta ao tratamento (presença ou ausência de resistência), presença ou ausência de disfunção renal e mecanismos imunológicos. ${ }^{3}$

A forma mais comum de rejeição aguda ao enxerto é iniciada quando aloantígenos do doador são apresentados aos linfócitos $\mathrm{T}$ do receptor por APCs.
As células dendríticas e os macrófagos apresentam antígenos para as células $T$ de forma eficiente, porém as células $B$ também podem desempenhar essa função capturando e apresentando antígenos com utilização de imunoglobulinas de superfície e moléculas de MHC de classe II. $\mathrm{O}$ ataque ao enxerto pode ocorrer na periferia ou nos órgãos linfoides terciários que se desenvolvem dentro do rim transplantado. ${ }^{3}$

As células T são capazes de mediar a lesão ao enxerto diretamente através do contato com células epiteliais tubulares e através dos efeitos das citocinas liberadas localmente. Elas também podem prejudicar o enxerto indiretamente, através da ativação de células endoteliais vasculares ou inflamatórias. ${ }^{3}$

A prevenção e tratamento da rejeição estão centrados na imunossupressão, cuja principal função é inibir a ativação e as funções efetoras dos linfócitos T. Em transplantados renais, utilizam-se terapias de indução e de manutenção com imunossupressores geralmente em esquema tríplice. As principais classes de imunossupressores utilizados são: inibidores de calcineurina, antiproliferativos de linfócitos $T$ e antimetabólicos, corticosteroides e anticorpos monoclonais. Atualmente, a terapia de escolha para transplantado renal inclui: ciclosporina, azatioprina, micofenolato de mofetila, micofenolato de sódio, tacrolimo, sirolimo, everolimo, muromonabe CD3, basiliximabe, daclizumabe, imunoglobulina humana, imunoglobulina antitimócito, prednisona, prednisolona e metilprednisolona. ${ }^{20}$

Apesar de o risco global de rejeição aguda ter sido reduzido significativamente nos últimos anos em função da maior eficácia dos imunossupressores atuais, os episódios de rejeição aguda que ocorrem são mais graves do que eram antes e, infelizmente, as taxas de sobrevida do enxerto têm permanecido praticamente inalteradas. ${ }^{3}$

O equilíbrio entre as vantagens e desvantagens dos imunossupressores é usado para determinar a terapia de escolha. Porém, uma desvantagem comum entre os medicamentos dessa classe é o comprometimento do sistema imunológico do paciente, o que favorece o aumento da incidência de neoplasias e a incidência de eventos infecciosos. ${ }^{7}$

Aproximadamente, $80 \%$ dos receptores renais apresentam alguma complicação infecciosa durante 0 primeiro ano de acompanhamento após o transplante. ${ }^{7}$

De acordo com um estudo realizado por Souza et al (2010), em que avaliou-se a incidência e os fatores de risco para complicações infecciosas no primeiro ano após o transplante renal, $49 \%$ dos pacientes desenvolveram algum evento infeccioso, sendo que $12 \%$ corresponderam à infecção por citomegalovírus. ${ }^{7}$ 


\section{Infecção e doença citomegálica}

O citomegalovírus, ou herpes vírus humano tipo 5 (HHV-5), é constituído de uma fita dupla de ácido desoxirribonucleico (em inglês, deoxyribonucleic acid, DNA) contido no interior de um capsídeo icosaédrico. Esse capsídeo é revestido por uma camada amorfa de proteínas, chamada de tegumento, que por sua vez está coberta por um envelope composto por glicoproteínas virais. ${ }^{21,22}$

O vírus infecta leucócitos, sendo disseminado para todo o organismo através dessas células. A entrada do vírion na célula humana envolve a fusão da membrana celular externa do hospedeiro e as glicoproteínas presentes no envelope viral. Uma vez ocorrida essa fusão, o capsídeo contendo o genoma viral e as proteínas do tegumento são lançadas para o interior da célula. ${ }^{23}$

A infecção citomegálica provoca um impacto severo na célula. O CMV tem por característica a replicação lenta, que ocorre entre 14 e 24 horas após a entrada na célula e leva a uma séria desregulação no ciclo genético celular, causando mudanças na forma, no metabolismo e na transcrição genética da célula. ${ }^{24} \mathrm{O}$ ciclo replicativo pode ser divido em três fases, baseado no aparecimento sequencial de classes de proteínas virais específicas: precoce imediata, precoce e tardia. ${ }^{22}$

A fase precoce imediata ocorre nas primeiras quatro horas após a infecção, com transcrição restrita de fragmentos específicos do DNA e a produção de proteínas regulatórias, que permitem ao vírus controlar a síntese de macromoléculas da célula hospedeira. Nessa fase são observadas as proteínas precoces imediatas, como a pp65, que constituiu uma das mais imunogênicas do vírus. ${ }^{22}$

O período seguinte persiste por mais de 24 horas e é caracterizado pela replicação contínua de grande parte do DNA viral. Nessa fase são sintetizadas proteínas como a DNA polimerase. ${ }^{22}$

O período tardio ocorre de 36 a 48 horas após a infecção. Proteínas estruturais do vírus são produzidas, ocorrendo a formação e liberação de vírions. ${ }^{22}$

O CMV é muito prevalente na população mundial, estimando-se que entre 40 e $100 \%$ dos adultos apresentam sorologia positiva (IgG) para esse patógeno. ${ }^{25}$

A infecção primária ocorre geralmente na infância e pode ser assintomática ou apresentar-se com um quadro de febre alta e prolongada, astenia, sudorese, cefaleia e hepatoesplenomegalia em cerca de $50 \%$ dos casos. As enzimas hepáticas encontram-se elevadas em aproximadamente $80 \%$ dos casos de doença grave. Em transplantados renais, a infecção ativa ocorre geralmente entre o primeiro e o terceiro mês pós- transplante e as manifestações clínicas atribuíveis são: febre, leucopenia, trombocitopenia e presença de linfócitos atípicos. Alguns dias após a febre, verificam-se aumento nos níveis séricos da aspartato aminotransferase (AST), o aparecimento de sintomas respiratórios, epigastraldia, náusea e diarreia. ${ }^{25}$

Uma característica peculiar do CMV é a capacidade de permanecer latente após a infecção primária. Em diferentes circunstâncias de baixa vigilância imunológica, o vírus pode ser reativado, como, por exemplo, em pacientes que fazem uso de terapia imunossupressora. Sabe-se ainda que o CMV existe sob diferentes subtipos geneticamente distintos, para os quais a proteção imunológica cruzada é, no máximo, parcial.24 Assim, esse é um vírus capaz de causar infecção primária, reativação de infecção latente e reinfecção por um subtipo viral diferente, podendo evoluir para um quadro de doença citomegálica, marcado por pneumonite, hepatite, retinite ou doença gastrointestinal. ${ }^{25}$

Um estudo recente realizado por Helantera e colaboradores (2014), em que $19 \%$ dos transplantados renais apresentaram doença citomegálica, aponta sintomas gastrointestinais e febre como as mais comuns, ao passo que supressão da medula óssea e hepatopatia foram vistas com menos frequência entre os casos estudados. ${ }^{26}$

Além das complicações clínicas já citadas, a relação entre infecção ativa por CMV e rejeição ao enxerto tem sido objeto de vários estudos, porém os efeitos da infecção sobre a função do órgão transplantado e o risco de rejeição aguda são conflitantes. Alguns estudos mostram uma associação entre a infecção e o aumento no índice de perda do enxerto; ${ }^{9,10,27}$ enquanto outros não encontram associação entre esses eventos. ${ }^{28-30}$

$\mathrm{Na}$ fase aguda da infecção, o vírus pode ser encontrado em macrófagos, linfócitos $T$ e $B$ e neutrófilos circulantes. Células mononucleares fagocíticas do sangue periférico e polimorfonucleares são as primeiras a atuarem na resposta imunológica, mas também contribuem para a disseminação viral no hospedeiro. O envolvimento dos leucócitos circulantes com as células endoteliais dos órgãos desencadeia uma resposta inflamatória, o que resulta no aumento da expressão de moléculas, facilitando a aderência dos leucócitos e a passagem transendotelial até os órgãos. Assim, ocorre a disseminação viral para o baço, glândulas adrenais, fígado, pulmões e glândulas salivares. Os polimorfonucleares são as primeiras células a expressar o antígeno estrutural pp65, que é utilizado para monitorar pacientes com risco de doença. ${ }^{22}$

A pp65 é a maior e mais abundante proteína no tegumento viral responsável pela modulação da resposta imune do hospedeiro durante a infecção; e também é o principal 
constituinte do vírion, embora não seja essencial para a produção de novas partículas virais infecciosas. Essa proteína está implicada na neutralização de ambas as respostas inata e adaptativa durante o processo infeccioso. Nesse processo, a proteína é capaz de impedir o reconhecimento das proteínas antigênicas imediatas precoces pelo hospedeiro, além de inibir a síntese de vários componentes envolvidos na resposta imune. ${ }^{22}$

Um dos mecanismos adotados pela pp65 como forma de modular a imunidade adaptativa é exercer a atividade quinase, mediando a fosforilação de proteínas imediatas do ciclo viral, com consequente bloqueio da sua apresentação às moléculas do $\mathrm{MHC}$ de classe I. A atividade quinase da pp65 também tem sido implicada na degradação da cadeia alfa da molécula HLA-DR. ${ }^{22}$

Outra ação da pp65 contra o sistema imune é a inibição da citotoxicidade das células exterminadoras naturais. Especificamente, foi demonstrado que a pp65 pode atuar como um ligante antagonista ao NKp30, ativando receptores que inibem a deleção de células infectadas, bem como interferir na comunicação entre as células exterminadoras naturais e as células dendríticas. ${ }^{22}$

Além disso, há evidências de que a pp65 está envolvida na mediação de uma diminuição na expressão de moléculas do MHC e na atenuação da resposta do interferon beta. ${ }^{22}$

Resumidamente, a proteína pp65 utiliza-se de diversos mecanismos com um objetivo principal: evitar a destruição das células infectadas pelo sistema imune hospedeiro e, para tanto, desempenha importante papel na modulação da resposta imune. ${ }^{22}$

Torna-se evidente o potencial de morbidade e de mortalidade que 0 vírus assume em pacientes transplantados, uma vez que há alta prevalência do vírus na população em geral e a potente terapia imunossupressora é essencial para o sucesso do transplante. Dessa forma, o risco para infecção ativa e doença citomegálica após o transplante é determinado por dois fatores: a epidemiologia viral e a imunidade do hospedeiro. ${ }^{31}$

\section{Fatores de risco para o desenvolvimento de doença citomegálica pós-transplante renal}

Os fatores de risco associados ao desenvolvimento de doença citomegálica após o transplante estão bem definidos. Um dos mais significativos é o status sorológico do doador e do receptor. São considerados casos de alto risco aqueles em que o doador é soropositivo para CMV e o receptor não apresenta evidência sorológica de infecção prévia pelo vírus (nesse caso designado por $D+/ R$ ). Isso porque receptores soronegativos carecem de anticorpos preexistentes específicos ao CMV, o que resulta em um quadro de infecção primária, com intensa dinâmica de replicação do vírus e incapacidade do hospedeiro para suprimir a ação viral. ${ }^{31}$ Esse tipo de infecção ocorre em $20 \%$ dos pacientes e é o quadro mais preocupante, uma vez que pode assumir maior gravidade, dependendo do estado de imunossupressão do indivíduo, da precocidade do diagnóstico e da resposta a terapia empregada. ${ }^{24,32}$

Receptores renais com marcadores sorológicos positivos para o vírus podem sofrer reativação viral ou reinfecção com evolução para formas mais leves da doença, a não ser que recebam imunossupressão muito intensa como, por exemplo, no tratamento da rejeição aguda. ${ }^{24,32}$ Outros fatores de risco são: idade avançada, co-morbidades associadas, neutropenia, episódios de rejeição e incompatibilidade HLA..$^{10,27}$

O protocolo imunossupressor é um importante fator de risco a ser considerado. Sabe-se que os imunossupressores utilizados na terapia póstransplante renal têm níveis de influência distintos sob o desenvolvimento de doença por $\mathrm{CMV}^{27}$

Estudos mostram que o uso de anticorpos depletores de linfócitos $\mathrm{T}$, como a imunoglobulina antitimócito, o muromonabe CD3 e o alentuzumabe, principalmente no tratamento de rejeição aguda, estão significativamente associados à ocorrência de doença citomegálica. ${ }^{27,33-37}$ Mais recentemente, a ciclosporina também tem apresentado uma forte associação. ${ }^{29,35}$

Em um estudo realizado por Souza et al (2010), a análise de regressão logística confirmou que a utilização dos imunossupressores micofenolato de mofetila (OR 2,33, IC 1,87-2,90), muromonabe CD3 (OR 2,38, IC 1,40-4,04) e imunoglobulina antitimócito (OR 2,91, IC 1,51 - 5,58) é fator de risco significativo para a ocorrência de episódios infecciosos, sendo a imunoglobulina antitimócito a que apresentou risco mais significativo entre as terapias. ${ }^{7}$ Isso se deve, provavelmente, ao fato da potência dessa terapia, que tem sido utilizada no tratamento de rejeição aguda grave e como terapia de indução em transplante com risco imunológico maior.

Nesse mesmo estudo, a variável que apresentou associação mais significativa com a ocorrência de complicações infecciosas foi o transplante a partir de doadorfalecido (OR 3,299, IC 2,373 -4,585). A justificativa para essa associação pode ser em detrimento do uso de doses maiores de imunossupressores na indução e na manutenção do transplantado que recebe órgão de doador falecido e, também, pela intensa terapia imunossupressora utilizada no tratamento de rejeições decorrentes do tempo prolongado de isquemia tecidual. ${ }^{7}$ 
Outro fator de risco que pode ser preocupante no desenvolvimento de doença citomegálica é o uso de hemoderivados obtidos de doadores soropositivos para CMV em receptores com ou sem exposição prévia ao vírus. ${ }^{27}$

Torna-se, dessa forma, evidente a importância de definir quem são os pacientes de alto risco para o desenvolvimento de infecção ativa, através da triagem pré-transplante e, assim, estabelecer a melhor estratégia terapêutica para evitar a evolução do quadro para doença citomegálica. ${ }^{32}$

\section{Comparação entre as duas principais técnicas de diagnóstico de infecção citomegálica ativa}

O diagnóstico de replicação viral ou infecção ativa tem sido realizado pela técnica de antigenemia pp65, em leucócitos do sangue periférico, ou por testes de ácidos nucleicos (NAT) através da técnica de PCR, e vem sendo utilizado para identificar com maior precocidade indivíduos que vão evoluir para a doença citomegálica e, dessa forma, diminuir a sua gravidade. Os métodos sorológicos para detecção de imunoglobulinas das classes IgM e IgG e as culturas virais têm sido pouco utilizados na prática clínica em função do tempo excessivo para a obtenção do resultado e da baixa sensibilidade. ${ }^{31}$

A antigenemia pp65 é um método semi-quantitativo em que se detecta, através de imunohistoquímica ou imunofluorescência, a presença do antígeno precoce de matriz do CMV, a fosfoproteína 65 (codificada por UL83), expressa em leucócitos do sangue periférico. Os resultados do ensaio são expressos no número de células positivas pelo total analisado. ${ }^{12,31}$

A quantificação da carga viral com base no número de células infectadas pode indicar a gravidade da infecção: quanto maior o número de células pp65 positivas, maior é a gravidade da doença ou risco de progressão da doença citomegálica. ${ }^{31}$

A limitação eventual desse teste está na definição do limite de positividade, uma vez que os critérios para diferenciar infecção e doença citomegálica são distintos, podendo variar entre os centros de diagnóstico. GómezMarqués et al consideram que para o diagnóstico de infecção ativa, uma antigenemia pp65 > 1 célula/100.000 leucócitos é significativa. Já para a doença citomegálica o ponto de corte varia de acordo com a sorologia do paciente; se o paciente for soronegativo, o diagnóstico de risco de doença é evidenciado por antigenemia pp65 $>1$ célula/100.000 leucócitos. No caso do paciente soropositivo, o risco para a doença é evidenciado por antigenemia $>10$ células $/ 100.000$ leucócitos. ${ }^{38}$

Em média, a antigenemia pode ser detectada de cinco a 14 dias antes do início dos sinais e sintomas da doença e, por isso, tem sido usada para guiar uma das estratégias terapêuticas atuais na prevenção da doença citomegálica - a terapia preemptiva. Nessa estratégia, os pacientes são monitorados regularmente (normalmente uma vez por semana) durante três meses após o transplante, para a presença de células pp65 positivas. Uma vez que as células positivas são detectadas em um limiar pré-definido e antes do início da sintomatologia clínica, os pacientes são tratados com antivirais, a fim de impedir a progressão da infecção assintomática para doença clínica. ${ }^{31}$

Inúmeros pontos de corte têm sido considerados para o início da terapia antiviral com base na sensibilidade e especificidade de cada método; no entanto, de um modo geral para transplantados renais, tem-se 10 células positivas/200.000 leucócitos como valor preditivo para o início do tratamento, com base na antigenemia por imunofluorescência. ${ }^{12,31,39}$

As principais vantagens da antigenemia são: a alta sensibilidade e especificidade. Entretanto, exige pessoal treinado para esse fim, além do processamento do sangue dentro de seis a oito horas após a coleta. Somado a isso, a antigenemia pode apresentar decréscimo de sensibilidade na presença de neutropenia..$^{10,27,40}$

Por outro lado, as técnicas moleculares têm sido cada vez mais frequentemente incorporadas ao diagnóstico laboratorial de CMV. Para esse fim, dois tipos de testes estão atualmente disponíveis: o PCR convencional de natureza qualitativa e o PCR em tempo real, de natureza quantitativa. ${ }^{27,40}$

Pela baixa especificidade e pela incapacidade de distinção entre infecção ativa e latente, o PCR qualitativo é uma opção para diagnóstico apenas se esse for 0 único método disponível. ${ }^{31,40}$

Em contrapartida, o PCR quantitativo tem correlacionado doença e gravidade da infecção com o grau de replicação viral. A infecção ativa por CMV é indicada por altos valores de carga viral ou uma tendência crescente da carga viral detectados no PCR, enquanto que as cargas virais de baixo nível podem indicar presença do vírus latente. ${ }^{31}$

$\mathrm{Da}$ mesma forma que na antigenemia, alguns pontos de corte têm sido considerados para o início da terapia antiviral com base nos testes realizados com PCR.38 Em um estudo realizado por Martín-Gandul e colaboradores (2013) estabeleceu-se uma carga viral de $3.983 \mathrm{UI} / \mathrm{mL}$ ( 2.600 cópias $/ \mathrm{mL}$ ) para iniciar o tratamento, através do acompanhamento de aproximadamente 200 pacientes por PCR em tempo real. ${ }^{41}$

Existe boa correlação entre os níveis de PCR quantitativo e os resultados de antigenemia, com maior sensibilidade 
do PCR, mas com redução da especificidade. $\mathrm{Na}$ comparação com a antigenemia, a realização de PCR tem a vantagem de poder ser realizado em pacientes leucopênicos, ter a possibilidade de automatização com processamento de várias amostras ao mesmo tempo e de usar material com tempo de coleta superior a oito horas. Entretanto, essas técnicas exigem equipamentos e reagentes de alto custo, em especial na modalidade de PCR em tempo real. ${ }^{31}$

Fatores como neutropenia, baixa carga viral e tratamento antiviral têm sido implicados como potenciais contribuintes para resultados discordantes entre a antigenemia e as técnicas com PCR. ${ }^{42}$

Em relação ao monitoramento da resposta ao tratamento, o PCR quantitativo tem se mostrado mais preciso. Geralmente, o número de leucócitos pp65 positivos diminui durante o tratamento antiviral eficaz. No entanto, pode haver aumento intermitente no nível de antigenemia durante as primeiras duas semanas de tratamento antiviral. O mecanismo para esse aumento não é completamente compreendido, mas não sugere necessariamente falha do tratamento enquanto 0 paciente apresenta melhora clínica. De modo geral, o tratamento antiviral é continuado até que células pp65 positivas não sejam mais detectadas no sangue; porém a persistência ou aumento do número dessas células pode indicar vírus resistentes à terapia antiviral ou a necessidade de reduzir a imunossupressão. ${ }^{31}$

Atualmente, considera-se que tanto a antigenemia, quanto o PCR quantitativo podem ser utilizados para a monitorização na terapia preemptiva, diagnóstico de doença ou para monitorização da resposta à terapia antiviral. A escolha entre um dos métodos depende basicamente da disponibilidade de recursos humanos $\mathrm{e}$ econômicos nas diferentes instituições e do bom senso clínico para estabelecer as melhores medidas a serem tomadas frente a cada paciente..$^{10,27,40,43}$

\section{Atuais estratégias de tratamento}

Em relação às estratégias de tratamento, o primeiro ponto a ser considerado é a prevenção da infecção e da doença citomegálica. Atualmente, a existência de estratégias para a prevenção de infecção citomegálica ativa reduziu significativamente a ocorrência de doença por CMV e também os efeitos indiretos da infecção após o transplante renal, aumentando as chances de sucesso do procedimento. As duas principais estratégias comumente empregadas são: profilaxia universal e terapia preemptiva. Há uma variação significativa na aplicação clínica dessas estratégias entre os centros de diagnóstico e transplantes, e cabe ressaltar que, enquanto a profilaxia é uma estratégia que visa prevenir a infecção citomegálica, a terapia preemptiva tem como papel principal a prevenção da doença pelo CMV. ${ }^{44}$

A profilaxia universal envolve a administração de antivirais para todos os pacientes considerados de alto risco logo no início do período pós-transplante. Incluem-se nesse grupo o quadro D+/R- e os pacientes sob terapia de indução com globulina antitimocitária ou sob o uso de anticorpo monoclonal murino anti-CD3 há um ano. ${ }^{45}$ De acordo com o Kidney Disease: Improving Global Outcomes (KDIGO) publicado em 2009, é recomendada a quimioprofilaxia com valganciclovir ou ganciclovir oral, por pelo menos três meses após o transplante, e durante seis semanas após o tratamento com um anticorpo depletor de células T. ${ }^{46}$

No caso da terapia preemptiva, o monitoramento laboratorial pós-transplante é realizado em intervalos regulares para detectar a replicação viral precoce; uma vez que a replicação viral atinge um determinado limiar no ensaio, antes do desenvolvimento de sintomas, o tratamento antiviral é iniciado para evitar a progressão para doença clínica. Essa abordagem terapêutica tem sido considerada mais racional em relação à profilaxia. ${ }^{27}$

Enquanto a terapia preemptiva tem a vantagem de reduzir o número de pacientes expostos a medicamentos antivirais, custos, o tempo de tratamento e a toxicidade relatada pelo uso de antivirais, a profilaxia previne a reativação de outros herpes vírus e reduz a incidência de efeitos indiretos da infecção citomegálica. ${ }^{27,31}$

Nos casos em que o tempo de replicação viral é muito rápido (especialmente com $D+/ R-$ ) pode haver tempo insuficiente para constituir um tratamento inicial para a infecção por CMV, antes do desenvolvimento dos sintomas ou da doença. Coordenar a logística de triagem de rotina, revisando resultados, iniciar a terapia rapidamente após ensaios positivos, e fazer o acompanhamento e posterior gestão pode ser difícil para alguns centros de diagnóstico. ${ }^{27}$

Até o presente momento, não está estabelecido qual das duas estratégias tem melhor relação custo-efetividade. Há vantagens e desvantagens entre as duas, entretanto após o estabelecimento da profilaxia universal, houve um aumento considerável de doença por CMV de início tardio, bem como do risco de desenvolvimento de resistência ao ganciclovir. ${ }^{47,48}$ Arthurs e colaboradores (2008) ao estudarem a doença citomegálica tardia em casos de $D+/ R-$, em que todos os pacientes receberam profilaxia ganciclovir, notaram que nenhum dos receptores desenvolveu infecção sob o uso da profilaxia, no entanto $29 \%$ do pacientes desenvolveram a doença, em média, 61 dias após a interrupção do tratamento antiviral. ${ }^{47}$ Sob a mesma perspectiva, Browne e colaboradores (2010) obtiveram um resultado de $20 \%$ 
de pacientes que desenvolveram doença tardia, após um ano do transplante renal, sendo que em $34 \%$ dos casos ocorreu infecção recorrente. ${ }^{48}$

Os fatores de risco para a recidiva da infecção por CMV incluem: infecção primária por CMV, transplante a partir de doador falecido, presença de alta carga viral inicial, lenta redução da carga viral no tratamento, viremia persistente quando em profilaxia secundária e tratamento para rejeição ao enxerto concomitante com o tratamento antiviral. ${ }^{47,48}$

No caso de doença citomegálica estabelecida entre leve e moderada, o tratamento pode ser realizado com valganciclovir ou ganciclovir intravenoso. O valganciclovir mostrou-se uma alternativa com base na equivalência das concentrações plasmáticas obtidas quando comparado ao ganciclovir. ${ }^{27}$ Nos casos de doença grave é recomendado o tratamento com ganciclovir intravenoso; além disso, sugere-se a redução da potência imunossupressora em pacientes com doença citomegálica com risco de vida ou doença persistente em face do tratamento, até que a doença por CMV tenha sido resolvida. É importante que as doses sejam administradas corretamente e ajustadas de acordo com a função renal de cada paciente, visto que uma terapia inadequada pode resultar em falha de eficácia clínica e no desenvolvimento de resistência, ou ainda, em casos de superdosagem, no aumento da toxicidade. ${ }^{46}$

A duração do tratamento é determinada pelo monitoramento semanal da carga viral do CMV e o tratamento deve ser continuado até que uma ou duas amostras consecutivas sejam negativas. Dessa forma, o risco de desenvolvimento de resistência e a ocorrência de recidiva são minimizados. Monitoramento mais frequente da carga viral não demonstrou qualquer valor terapêutico adicional. ${ }^{46}$
A partir da segunda recidiva ou em casos de resistência ao tratamento com ganciclovir, a substituição dos imunossupressores tacrolimo ou micofenolato por um dos inibidores da mTOR (mammalian target of rapamycin), como o sirolimo ou o everolimo, deve ser considerada. Estudos mostram que tal combinação de imunossupressores com 0 antiviral pode ter impacto positivo sobre a incidência de doença citomegálica. ${ }^{49,50}$

Em suma, cabe à equipe médica, junto ao centro de diagnóstico, definir qual a melhor estratégia terapêutica a ser adotada. Pelo fato da profilaxia universal estar sendo relacionada a um aumento considerável da doença citomegálica de início tardio e com um risco maior de desenvolvimento de resistência ao ganciclovir, torna-se racional adotar a estratégia de tratamento preemptivo, ficando a profilaxia reservada para casos específicos, de acordo com a definição da equipe médica, após o transplante renal. ${ }^{3}$

\section{CONSIDERAÇÕES FINAIS}

A infecção citomegálica ainda é um problema preocupante nos centros de transplante do mundo. Avanços tecnológicos no diagnóstico e no arsenal terapêutico não foram suficientes para reduzir a taxa de prevalência da infecção em transplantados renais; e ainda, casos de reativação viral após um ano de terapia profilática e de resistência aos antivirais têm se tornado mais comuns. Dessa forma, o desafio atual é definir dentre os recursos diagnósticos e os protocolos antivirais qual o mais adequado para cada situação clínica, priorizando a racionalização terapêutica, através da avaliação do custo do tratamento e dos efeitos adversos e tardios advindos de seu emprego.

\section{ABSTRACT}

Kidney transplantation is the most frequently transplantation globally. carried out. However, although kidney transplants have in most cases positive results, the continuing use of immunosuppressive drugs could pose a negative impact on the patient, leaving him susceptible to infectious complications. A major complication is the cytomegalovirus infection that occurs mainly in the first three months after transplantation, an important morbidity and mortality cause in those patients. Currently, to reduce the risk of cytomegalovirus disease there are two therapeutic strategies: preemptive therapy and prophylaxis. However, despite the therapeutic protocols are established, viral resistance and relapse of the cytomegalovirus disease have put them again in debate. In this context, the aim of the study is to perform a narrative review on the cytomegalovirus infection in kidney transplant, addressing the viral characteristics in the development of the cytomegalovirus infection and disease, as well as the risk factors and impact on the patient, the preference for the antigenemia pp65 method or the use of nucleic acid testing (NAT) for the diagnosis and current treatment strategies. For this review, the databases were consulted, being selected current articles with relevant matter to the subject.

Keywords: Cytomegalovirus, Cytomegalovirus Infections, Kidney Transplantation 


\section{REFERÊNCIAS}

1.World Health Organization (WHO). Transplantation: Human organ transplantation. 2014. Disponível em: <http://www. who.int/transplantation/organ/en/> Acesso em: 15 out. 2014.

2.Registro Brasileiro de Transplantes (RBT). Dimensionamento dos transplantes no Brasil e em cada estado (2006 - 2013). Veículo oficial da Associação Brasileira de Transplante de Órgãos, 2013.

3.Nankivell BJ, Alexander SI. Rejection of the kidney allograft. N Engl J Med. 2010;363:1451-62.

4.Rezende JM. Imunodepressão, imunossupressão. Rev Pat Trop. 2011;40(2):199-201.

5.Noronha IL, Manfro RC, Pacheco-Silva A, Casadei D. Manual de Transplante Renal. 1st ed. São Paulo: Manole; 2007.

6. Heilman RL, Mazur MJ, Reddy KS. Immunosuppression in simultaneous pâncreas-kidney transplantation: progress to date. Drugs. 2010;70(7):793-804.

7.Sousa SR, Galante NZ, Barbosa DA, Pestana JOM. Incidência e fatores de risco para complicações infecciosas no primeiro ano após o transplante renal. J Bras Nefrol. 2010;32(1):77-84.

8.Kute VB, Vanikar AV, Shah PR, Gumber MR, Patel HV, Godara $\mathrm{SM}$, et al. Post-renal transplant cytomegalovirus infection: study of risk factors. Transplant Proc. 2012;44:706-709.

9.Cordero E, Casasola C, Ecarma R, Danguilan R. Cytomegalovirus disease in kidney transplant recipients: incidence, clinical profile, and risk factors. Transplant Proc. 2012;44:694-700.

10.De Keyzer k, Van Laecke S, Peeters P, Vanholder R. Human cytomegalovirus and kidney transplantation: a clinician's update. Am J Kidney Dis. 2011;58:118-26.

11.Fischer RA. Cytomegalovirus infection and disease in the new era of immunosuppression following solid organ transplantation. Transpl Infect Dis. 2009;11(3):195-202.

12.Schroeder RB, Michelon T, Wurdig J, Keitel E, Neumann J. Comparação entre técnicas de imunoistoquímica e de imunofluorescência para antigenemia pp65 do citomegalovírus (CMV) em receptores de transplante. J Bras Transpl. 2009;12:1101-4.

13.White SL, Chadban SJ, Jan S, Chapman JR, Cass A. How can we achieve global equity in provision renal replacement therapy? Bull World Health Organ 2008;86:229-37.

14. Mathur AK, Ashby VB, Sands RL, Wolfe RA. Geographic variation in end-stage renal disease incidence and access to deceased donor kidney transplantation. Am J Transplant. 2010;10:1069-80.

15.Registro Brasileiro de Transplantes (RBT). Dados Numéricos da doação de órgãos e transplantes realizados por estado e instituição no período: janeiro/setembro - 2014. Veículo oficial da Associação Brasileira de Transplante de Órgãos, 2014.

16.Castro MCR. Manual de transplante renal. Disponível em: <http://www.abto.org.br/abtov03/default.aspx?mn=478\&c=9 $19 \& s=0 \&$ friendly=manuais-de-transplantes $>$ Acesso em: 15 out. 2014.
17.Kalble T, Alcaraz A, Budde K, Humke U, Karam G, Lucan $M$, et al. Guidelines on renal transplantation. European Association of Urology. 2010.

18. Abbas AK, Lichtman AH. Cellular and Molecular Immunology. Londres: Elsevier; 2008.

19. Avery RK. Infectious Disease Following Kidney Transplant: Core Curriculum 2010. Am J Kidney Dis. 2010;55(4):755-71.

20.Brasil. Ministério da Saúde. Portaria $n^{\circ} 712$, de 13 de agosto de 2014. Aprova o Protocolo Clínico e Diretrizes Terapêuticas da Imunossupressão no Transplante Renal. Diário Oficial da União. Brasília, DF, 14 de ago. 2014.

21.Mocarski ES, Shenk T, Passa RF. Cytomegaloviruses. In Fields virology. 5th ed. Philadelphia, PA: Lippincott Williams; 2007.

22.Tomtishen JP. Human cytomegalovirus tegument proteins (pp65, pp71, pp150, pp28). Virol J. 2012; 9:22.

23.Shenk T, Stinski FM. Human cytomegalovirus. Current topics in microbiology and immunology. 1st ed. Berlin: Springer; 2008.

24.Junqueira JJM, Sancho TM, Santos VA. Citomegalovírus: Revisão dos Aspectos Epidemiológicos, Clínicos, Diagnósticos e de Tratamento. 86th ed. 86. NewsLab; 2008.

25.Boeckh M, Gaballe AP. Cytomegalovirus: pathogen, paradigm and puzzle. J Clin Invest. 2011;121:1673-80.

26. Helantera I, Schachtner T, Hinrichs C, Salmela K, Kyllönen $\mathrm{L}$, Koskinen P, et al. Current characteristics and outcome of cytomegalovirus infections after kidney transplantation. Transpl Infect Dis. 2014;16(4):568-77.

27.Kotton CN, Kumar D, Caliendo AM, Asberg A, Chou S, Danziger-Isakov L, et al. Updated International Consensus Guidelines on the Management of Cytomegalovirus in Solid-Organ Transplantation. Transplantation. 2013;96:333-60.

28.Cukuranovic J, Ugrenovic S, Jovanovic I, Visnjic M, Stefanovic V. Viral Infection in Renal Transplant Recipients. ScientificWorldJournal 2012.

29.Einollahi B. Cytomegalovirus Infection following Kidney Transplantation: a Multicenter Study of 3065 Cases. Int J Org Transplant Med. 2012;3(2):74-8

30.Van Ree RM, Vries APJ, Zelle DM, Vries LV, Oterdoom $\mathrm{LH}$, Gans RO, et al. Latent cytomegalovirus infection is an independent risk factor for late graft failure in renal transplant recipients. Med Sci Monit. 2011;17(11):609-17.

31.Razonable RR, Hayden RT. Clinical Utility of Viral Load in Management of Cytomegalovirus Infection after Solid Organ Transplantation. Clin. Microbiol. Rev. 2013;26(4):703.

32. Albert Eistein Hospital Israelita. Diretrizes Assistenciais. Protocolo de Tratamento de Infecção pelo Citomegalovírus (CMV). 2011.

33. Bhadauria D, Sharma RK, Kaul A, Prasad N, Gupta A, Gupta A, et al. Cytomegalovirus Disease in Renal Transplant Recipients: A Single-Center Experience. Indian J Microbiol. 2012;52(3):510-5. 
34.Kesiraju S, Paritala P, Rao Ch UM, Athmakuri SM, Reddy VS, Sahariah S. Anti-thymocyte Globulin versus Basiliximab Induction in Renal Transplant Recipients: Long-term Outcome. Saudi J Kidney Dis Transpl. 2014;25(1):9-15.

35. Almeida CC, Silveira MR, Araújo VE, Lemos LLP, Costa JO, Reis CAL, et al. Safety of Immunosuppressive Drugs Used as Maintenance Therapy in Kidney Transplantation: A Systematic Review and Meta-Analysis. Pharmaceuticals. 2013;6:1170-94.

36.Chen G, Gu J, Qiu J, Wang C, Fei J, Deng S, et al. Efficacy and safety of thymoglobulin and basiliximab in kidney transplant patients at high risk for acute rejection and delayed graft function. Exp Clin Transplant. 2013;11(4):310-4.

37.LaMattina JC, Mezrich JD, Hofmann RM, Foley DP, D'Alessandro AM, Sollinger HW, et al. Alemtuzumab as compared to alternative contemporary induction regimens. Transpl Int. 2012;518-26.

38.Gómez-Marqués G, Alonso A, Bayés B, Bernal G, Fernández AM, Franco $A$, et al. Diagnóstico de la infección por citomegalovirus. Nefrol Supl Ext. 2012;3(1):14-20.

39. Soares JLMF, Rosa DD, Leite VRS, Pasqualotto AC. Métodos diagnósticos: consulta rápida. 2 nd ed. Porto Alegre: Artmed, 2012.

40.Kotton CN. Management of cytomegalovirus infection in solid organ transplantation. Nat Rev Nephrol. 2010;6:711-21.

41. Martín-Gandul C, Pérez-Romero P, Sánchez M, Bernal $G$, Suárez $G$, Sobrino $M$, et al. Determination, validation and standardization of a CMV DNA cut-off value in plasma for preemptive treatment of CMV infection in solid organ transplant recipients at lower risk for CMV infection. J Clin Virol. 2013;56(1):13-8.

42.Rha B, Redden D, Benfield M, Lakeman F, Whitley RJ, Shimamura M. Correlation and Clinical Utility of pp65 Antigenemia and Quantitative Polymerase Chain Reaction Assays for Detection of Cytomegalovirus in Pediatric Renal Transplant Patients. Pediatr Transplant. 2012;16(6):627-37.
43.Farfán MJU, Torres JPT, Vergara AA, Donoso GW, Alba AG, Paris $C D$, et al. Comparación de las técnicas de reacción de polimerasa en cadena en tiempo real y antigenemia para la detección de citomegalovirus en sangre de niños sometidos a transplantes. Rev Chil Infect. 2011;28(2):113-7.

44.Millera GG, Kaplanb B. Prophylaxis versus Preemptive Protocols for CMV: Do They Impact Graft Survival? Am J Transplant. 2008; 8:913-4.

45.Ono G. Guia de condutas em infecção e doença por citomegalovírus em transplante de rim e rim/pâncreas. Grupo de Infecção em Transplante de Órgãos Sólidos Escola Paulista de Medicina. 2010.

46. Kasiske BL, Zeier MG, Chapman JR, Craig JC, Ekberg H, Garvey CA, et al. KDIGO clinical practice guideline for the care of kidney transplant recipients: a summary. Kidney International advance online publication 2009.

47. Arthurs SK, Eid AJ, Pedersen RA, Kremers WK, Cosio FG, Patel R, et al. Delayed-onset primary cytomegalovirus disease and the risk of allograft failure and mortality after kidney transplantation. Clin Infect Dis. 2008; 46:840.

48. Browne BJ, Young J, Dunn TB, Matas AJ. The impact of cytomegalovirus infection $\geq 1$ year after primary renal transplantation. Clin Transplant. 2010;24(4):572-7.

49.Silva HT, Cibrik D, Johnston T, Lackova E, Mange K, Panis C, et al. Everolimus Plus Reduced-Exposure CsA versus Mycophenolic Acid Plus Standard-Exposure CsA in Renal-Transplant Recipients. Am J Transplant. 2010;10:1401-3.

50.Lebranchu Y, Thierry A, Toupance O, Westeel PF, Etienne I, Thervet E, et al. Efficacy on Renal Function of Early Conversion from Cyclosporine to Sirolimus 3 Months After Renal Transplantation: Concept Study. Am J Transplant. 2009;9:1115-23. 